\title{
Gemcitabine and Carboplatin in Intensively Pretreated Patients with Metastatic Breast Cancer
}

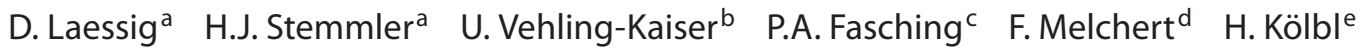

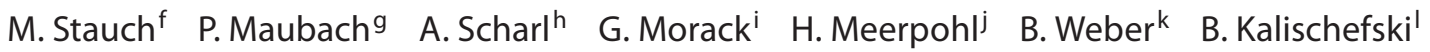

V. Heinemann ${ }^{a}$

a Department of Medicine III, Klinikum Grosshadern, University of Munich, Munich, ${ }^{\mathrm{b}}$ Schwerpunktpraxis, Landshut,

'University of Erlangen, Erlangen, 'University of Mannheim, Mannheim, e University of Mainz, Mainz,

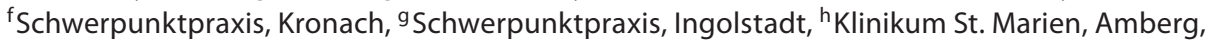

'Helios-Klinikum, Berlin, ${ }^{\mathrm{j} S t}$. Vincentius-Kliniken, Karlsruhe, ${ }^{\mathrm{K}}$ Klinikum Bad Trissl, Oberaudorf, and

'Schwerpunktpraxis, Waldmünchen, Germany

\section{Key Words}

Gemcitabine - Carboplatin - Anthracycline resistance •

Metastatic breast cancer

\begin{abstract}
Background: Patients with metastatic breast cancer (MBC) are increasingly exposed to anthracyclines and taxanes either during treatment of primary breast cancer or during initial therapy of metastatic disease. The combination of gemcitabine and carboplatin was therefore investigated as an anthracycline- and taxane-free treatment option. Patients and Methods: MBC patients previously treated with chemotherapy were enrolled in a multicenter phase II study. Treatment consisted of gemcitabine $\left(1,000 \mathrm{mg} / \mathrm{m}^{2}\right.$ i.v. on days 1 and 8) and carboplatin (AUC 4 i.v. on day 1) applied every 3 weeks. Results: Thirty-nine patients were recruited, and a total of 207 treatment cycles were applied with a median of 5 cycles per patient. One complete response and 11 partial responses were observed for an overall response rate of $31 \%$ (95\% Cl: 17-48\%). Twelve patients (31\%) had stable disease. Median time to progression was 5.3 months ( $95 \%$ Cl: 2.6-6.7 months) and median overall survival from start of treatment was 13.2 months ( $95 \% \mathrm{Cl}$ : 8.7-16.7 months). Grade 3/4 hematological toxicity included leukopenia $(59 \% / 5 \%)$, thrombo-
\end{abstract}

cytopenia (26\%/23\%) and anemia (10\%/0\%). Nonhematological toxicity was rarely severe. Conclusion: Combination chemotherapy with gemcitabine and carboplatin is an effective and generally well-tolerated treatment option for intensively pretreated patients with MBC. Due to a considerable incidence of severe thrombocytopenia it would be reasonable to consider starting gemcitabine at the lower dose level of $800 \mathrm{mg} / \mathrm{m}^{2}$.

Copyright $\odot 2008$ S. Karger AG, Basel

\section{Introduction}

As anthracycline- and also taxane-based regimens have become a standard of care for patients with primary breast cancer in the neoadjuvant and adjuvant setting, the number of patients who have already been exposed to these drugs in the metastatic stage is increasing. Hence, the evaluation of alternative treatment strategies not cross-resistant to anthracyclines or taxanes is mandatory. At the same time, it is important to ensure that efficacy is improved at the lowest cost to quality of life.

Gemcitabine as a single agent has induced overall response rates of $0-37 \%$ in first-line treatment, whereas the response rates in the second- or third-line therapy were

\section{KARGER}

Fax +41613061234 E-Mail karger@karger.ch www.karger.com
(ㄷ) 2008 S. Karger AG, Basel

0030-2414/07/0736-0407\$23.50/0

Accessible online at:

www.karger.com/ocl
Prof. Dr. V. Heinemann

Medical Department III, Klinikum Grosshadern, University of Munich

Marchioninistrasse 15, DE-81377 Munich (Germany)

Tel. +49897095 0, Fax +498970958828

E-Mail Volker.Heinemann@med.uni-muenchen.de 
26 and 13\% [1-5]. In studies limited to second- or thirdline therapy after anthracycline and/or taxane exposure, response rates of $0-29 \%$ and median time to progression of 2- 6 months were reached [3-5].

Gemcitabine is an excellent choice for combination therapy because of its unique mechanism of action and its favorable profile of side effects. The combination of gemcitabine and cisplatin was shown to be effective in several trials, inducing response rates between 30 and $52 \%$ in patients pretreated with taxanes and/or anthracyclines [6-10].

To improve on tolerability and feasibility of the regimen, carboplatin may be the more appropriate choice for treatment of metastatic disease. In four phase II trials of previously untreated patients with metastatic breast cancer (MBC), single agent carboplatin induced objective response rates between 8 and 35\% [11-14]. Studies performed in various solid tumor types indicate comparable activity of cisplatin and carboplatin $[15,16]$.

It appears that resistance to platinum salts is induced by pretreatment, possibly by an upregulation of DNA repair. Gemcitabine, a known inhibitor of DNA repair, may overcome this form of resistance and thus provides an excellent rationale for the combination of both agents. Exposure to platinum salts causes an activation of DNA repair polymerases and thereby enhances the incorporation of gemcitabine triphosphates into DNA repair patches. Once integrated into DNA, gemcitabine is not readily recognized and excised by proofreading exonucleases and may trigger signaling pathways leading to apoptosis.

Several considerations support the use of gemcitabine and a platinum salt in the salvage treatment of MBC. First, in vitro studies indicate additive or synergistic activity which was most pronounced in platinum-resistant cell lines and was found to be due to an increased formation and an impaired repair of platinum-DNA adducts $[17,18]$. Second, gemcitabine and carboplatin are usually not included into adjuvant or neoadjuvant chemotherapy. Therefore, resistance to either drug is unlikely to occur. Third, studies investigating the combination have shown minimal overlapping toxicity suggesting an acceptable toxicity profile even in intensively pretreated patients [4, 19-21]. Finally, the addition of trastuzumab to gemcitabine/carboplatin might form an effective triplet combination [22].

The present multicenter phase II study was aimed to evaluate the efficacy and tolerability of gemcitabine applied on days 1 and 8 plus carboplatin applied on day 1 every 3 weeks in previously treated patients with MBC.

\section{Patients and Methods}

\section{Patient Population}

Thirty-nine patients with histologically confirmed MBC were recruited to participate in a study with a treatment protocol approved by the local ethics committee. All patients were required to give written informed consent prior to study entry.

Prior treatment with chemotherapy, hormonal therapy, immunotherapy or local radiotherapy was allowed. Patients were required with at least one bidimensionally measurable lesion outside a previous radiation port. Other eligibility criteria included age $\geq 18$ years, Karnofsky performance status $\geq 70 \%$, minimal life expectancy of 12 weeks, and adequate hematological, renal, cardiac and hepatic function [leukocyte count $\geq 3.0 \times 10^{9} / 1$ or absolute neutrophil count $\geq 2 \times 10^{9} /$; platelet count $\geq 100 \times$ $10^{9} / \mathrm{l}$; hemoglobin $\geq 8 \mathrm{~g} / \mathrm{dl}$; total serum bilirubin $\leq 1.25 \times$ upper limit of normal (ULN) in the absence of liver metastasis or $\leq 3.0$ $\times$ ULN in the presence of liver metastasis; transaminase (ALT, AST) level $\leq 3 \times$ ULN in the absence of liver metastasis or $\leq 5$ $\times$ ULN in the presence of liver metastasis; alkaline phosphatase level $\leq 2.5 \times \mathrm{ULN}$ ]. Creatinine clearance was required to exceed $60 \mathrm{ml} / \mathrm{min}$.

Patients were not eligible for study enrolment if they were pregnant, lactating or refused effective contraception, and if they had bone metastasis only, known brain metastases or a secondary malignancy, history of another primary malignant disease other than in situ carcinoma of the uterine cervix or adequately treated basal cell skin cancer, active infection or any other concomitant severe clinical condition making implementation of the protocol including prehydration difficult. Administration of other cytotoxic, immune or hormonal agents or radiation therapy was not permitted during the study, with the exception of contraceptives, corticosteroids given as antiemetic treatment, or local palliative radiation.

\section{Patient Assessment}

Patients were evaluated on a regular basis during treatment. The following assessments were performed before each 3-week cycle: physical examination, complete blood count, serum chemistry, and assessment of toxicities. During the initial phase of treatment, complete blood counts were performed twice weekly to determine the nadir values. If the hematological values had not recovered by the time of scheduled treatment, the complete blood count was repeated every week until recovery of leukocyte count to $3.0 \times 10^{9} / 1$ and platelets to $\geq 100 \times 10^{9} / 1$.

Baseline tumor assessment was performed within 2 weeks of the start of treatment using imaging procedures such as ultrasound, computerized tomography or magnetic resonance imaging. Tumor assessments were repeated after every two cycles of therapy, applying the initially used imaging procedure. World Health Organization (WHO) and NCI-CTC criteria (3.0) were used for the assessment of tumor response and toxicity grading $[23,24]$.

In addition, time to response (time from start of therapy to first documentation of objective response), duration of response (time from first documentation of objective response to first evidence of progressive disease), time to tumor progression (time from start of therapy to first evidence of progressive disease or last follow-up), and survival (time from start of therapy to death) were measured (intent-to-treat). 
Treatment Schedule

Treatment consisted of gemcitabine $1,000 \mathrm{mg} / \mathrm{m}^{2}$ given as a 30-min infusion on days 1 and 8 and carboplatin AUC 4 given as a 1-hour infusion on day 1 of a 3-week treatment cycle. Treatment was continued until disease progression or the occurrence of unacceptable toxicity.

Dose adjustments were made on the basis of leukocyte and platelet counts on the day of treatment and clinical assessments of nonhematological toxicities. The doses of both drugs were reduced by $25 \%$ if the leukocyte count was between 2.5 and $3.0 \times$ $10^{9} / \mathrm{l}$, while the platelet count exceeded $100 \times 10^{9} / \mathrm{l}$; if the leukocyte count was less than $2.5 \times 10^{9} / 1$ or the platelet count less than $100 \times 10^{9} / 1$, both drugs were omitted. Doses omitted on day 8 were not replaced and the next cycle was given on time as scheduled but at reduced doses. If any toxicity $\geq$ grade 3 except nausea/ vomiting or alopecia occurred, drug doses were reduced by $50 \%$. If the patient tolerated the dose-modified treatment well, a re-increase of the dose could be attempted in the following cycle. The use of hematopoietic growth factors was allowed in patients with prolonged hematopoietic recovery.

\section{Biometrical Analysis}

The primary objective of the study was to determine the objective response rate to the study treatment. Secondary end points included time to progression, survival, and toxicity. Simon's optimal two-stage design [25] was used to ensure that the number of patients exposed to this therapy was minimized should the therapy prove ineffective. The study was planned to distinguish between a clinically uninteresting response rate of $10 \%$ (null hypothesis) and a clinically interesting response rate of $30 \%$ (alternative hypothesis). With the type I error being 5\% and the type II error $10 \%, 18$ patients were to be enrolled during the first step and an additional 17 patients during the second step. If 2 or less responses occurred among the first 18 patients or 6 or less responses in the total population of 35 patients, the treatment had to be judged ineffective and enrolment stopped. If 7 or more responses were observed in the total patient population, the study treatment was judged effective. Assuming a dropout rate of $10 \%$, enrollment of a total of 39 patients was planned.

The 95\% confidence interval (CI) for the overall response rate was determined on the basis of the two-stage design. Time-toevent end points were calculated according to the method of Kaplan and Meier using the STATISTICA software [24, 25]. Patients who received at least one treatment cycle were evaluable for toxicity, and those who had received at least two treatment cycles or those who progressed after the first cycle were evaluable for response (intent-to-treat).

\section{Results}

\section{Patient Characteristics}

Thirty-nine eligible patients were recruited from 12 German centers. All patients were evaluable for response, toxicity and survival. Median age was 60 years (range 29-77). All patients had previously received chemotherapy, and 33 of them had received up to 5 prior
Table 1. Baseline patient characteristics $(n=39)$

\begin{tabular}{|c|c|c|}
\hline Variable & $\mathrm{n}$ & $\%$ \\
\hline \multicolumn{3}{|l|}{ Age, years } \\
\hline Median & \multicolumn{2}{|c|}{60} \\
\hline Range & \multicolumn{2}{|c|}{$29-77$} \\
\hline \multicolumn{3}{|l|}{ Karnofsky performance status, \% } \\
\hline $70-80$ & 7 & 18 \\
\hline $90-100$ & 32 & 82 \\
\hline \multicolumn{3}{|l|}{ Hormone receptor status } \\
\hline ER or PgR positive & 30 & 77 \\
\hline ER and PgR negative & 8 & 21 \\
\hline Unknown & 1 & 2 \\
\hline \multicolumn{3}{|l|}{ HER2 status (IHC) } \\
\hline 0 & 17 & 43 \\
\hline $1+$ & 7 & 18 \\
\hline $2+$ & 2 & 5 \\
\hline $3+$ & 10 & 26 \\
\hline Unknown & 3 & 8 \\
\hline \multicolumn{3}{|l|}{ Metastatic sites } \\
\hline 1 & 8 & 21 \\
\hline 2 & 13 & 33 \\
\hline$\geq 3$ & 18 & 46 \\
\hline \multicolumn{3}{|l|}{ Sites of metastases } \\
\hline Liver & 30 & 77 \\
\hline Lung & 13 & 33 \\
\hline Lymph nodes & 14 & 36 \\
\hline Bone & 21 & 54 \\
\hline CNS & 5 & 13 \\
\hline Other sites & 23 & 59 \\
\hline Skin, soft tissue or nodal disease only & 2 & 5 \\
\hline Bone disease only & 0 & 0 \\
\hline Visceral & 35 & 90 \\
\hline \multicolumn{3}{|l|}{ Tumor grading } \\
\hline G1 & 0 & 0 \\
\hline G2 & 17 & 44 \\
\hline G3 & 17 & 44 \\
\hline Unknown & 5 & 13 \\
\hline \multicolumn{3}{|l|}{ Prior treatment } \\
\hline Any CT & 39 & 100 \\
\hline CT for metastatic disease & 33 & 85 \\
\hline Adjuvant CT & 24 & 62 \\
\hline Taxane & 26 & 67 \\
\hline Anthracycline & 34 & 87 \\
\hline Anthracycline + taxane & 25 & 64 \\
\hline \multicolumn{3}{|l|}{ Number of prior CT regimens for $\mathrm{MBC}$} \\
\hline 0 & 6 & 15 \\
\hline 1 & 14 & 36 \\
\hline 2 & 8 & 21 \\
\hline$\geq 3$ & 11 & 29 \\
\hline
\end{tabular}

$\mathrm{CT}=$ Chemotherapy; ER = estrogen receptor; $\mathrm{PgR}=$ progesterone receptor; $\mathrm{IHC}=$ immunohistochemistry. 
chemotherapy regimens for metastatic disease. Twentysix patients $(67 \%)$ had previously received anthracyclines and 25 patients (64\%) both, an anthracycline- and a taxane-based regimen. Prior endocrine therapy in hormone receptor-positive patients had been applied to 31 patients $(80 \%)$. Twenty-six patients $(67 \%)$ had received tamoxifen, and 20 patients had received an aromatase inhibitor (51\%). Thirty-five patients presented with visceral metastases $(90 \%)$ and 31 patients $(79.5 \%)$ had more than one metastatic site.

Patient characteristics are shown in table 1.

\section{Treatment Delivery}

A total of 207 cycles of gemcitabine and carboplatin were delivered. Patients received a median number of 5 cycles (range: 1-12 cycles). Median duration of treatment was 3.8 months (range: 0.5-9.3 months). Dose reductions, delays and omissions occurred in 131 (63\%), 65 $(31 \%)$ and $36(17 \%)$ cycles, respectively.

\section{Response and Survival}

All patients were evaluable for efficacy (table 2). One patient achieved a complete response and 11 patients (28.2\%) a partial response, for an objective response rate of $30.8 \%$ (95\% CI: $17.0-47.6 \%$ ). Overall, disease control rate (objective response plus stable disease) was $61.5 \%$
(95\% CI: 44.6-76.6\%). Disease stabilization was achieved in 12 patients (30.8\%), lasting for more than 3 months in $11(28.2 \%)$ and for more than 6 months in 7 patients (17.9\%).

A detailed analysis of response with regard to baseline characteristics was undertaken (table 3). Response rate was higher in hormone receptor-positive and HER2-negative patients. Moreover, a higher response rate was observed in patients with one metastatic site only, with less than 3 prior treatment regimens for metastatic disease

Table 2. Efficacy of gemcitabine plus carboplatin

\begin{tabular}{lcrr}
\hline Parameter & Patients & \multicolumn{1}{c}{$\%$} & $95 \%$ CI \\
\hline CR & 1 & 2.6 & \\
PR & 11 & 28.2 & \\
SD & 12 & 30.8 & \\
$\quad$ SD $>3$ months & 11 & 91.7 & \\
$\quad$ SD $>6$ months & 7 & 58.3 & \\
PD & 12 & 30.8 & \\
ORR & 12 & 31.0 & $17-48 \%$ \\
$\quad$ DCR (CR+PR+SD) & 24 & 61.6 & \\
\hline
\end{tabular}

$\mathrm{CR}=$ Complete remission; $\mathrm{PR}=$ partial remission; $\mathrm{SD}=$ stable disease $\mathrm{PD}=$ progressive disease $; \mathrm{DCR}=$ disease control rate.
Table 3. Response rates by baseline characteristics

\begin{tabular}{|c|c|c|c|c|}
\hline \multirow[t]{2}{*}{ Variable } & \multirow{2}{*}{$\begin{array}{l}\text { Total } \\
\text { patients }\end{array}$} & \multicolumn{3}{|c|}{ Overall response } \\
\hline & & patients & $\%$ & $95 \% \mathrm{CI}$ \\
\hline \multicolumn{5}{|l|}{ Prior CTs for MBC } \\
\hline 0-2 (1st line, 2 nd line) & 28 & 11 & 39.3 & $21.5-59.4$ \\
\hline$>2$ (beyond 2nd line) & 11 & 1 & 9.1 & $0.2-41.3$ \\
\hline \multicolumn{5}{|l|}{ Metastatic sites } \\
\hline 1 & 8 & 5 & 62.5 & $24.5-91.5$ \\
\hline$\geq 2$ & 31 & 7 & 22.6 & $9.6-41.1$ \\
\hline \multicolumn{5}{|c|}{ Pretreatment with anthracycline and/or taxane } \\
\hline With anthracycline & 34 & 11 & 32.4 & $17.4-50.5$ \\
\hline With taxane & 26 & 7 & 26.9 & $11.6-47.8$ \\
\hline With both & 25 & 7 & 28.0 & $12.1-49.4$ \\
\hline Pretreatment without A/T & 14 & 5 & 35.7 & $12.8-64.9$ \\
\hline \multicolumn{5}{|l|}{ Hormone receptor status } \\
\hline ER and/or PgR positive & 30 & 10 & 33.3 & $17.3-52.8$ \\
\hline ER and PgR negative & 9 & 2 & 22.2 & $2.8-60.1$ \\
\hline \multicolumn{5}{|l|}{ HER2 status (IHC, DAKO) } \\
\hline Positive $(3+)$ & 10 & 2 & 20.0 & $2.5-55.6$ \\
\hline Negative $(0,1+, 2+$, unknown $)$ & 29 & 10 & 34.5 & $17.9-54.3$ \\
\hline
\end{tabular}

$\mathrm{CT}=$ Chemotherapy; $\mathrm{A}=$ anthracycline; $\mathrm{T}=$ taxane; $\mathrm{ER}=$ estrogen receptor; $\mathrm{PgR}=$ progesterone receptor; IHC $=$ immunohistochemistry. 


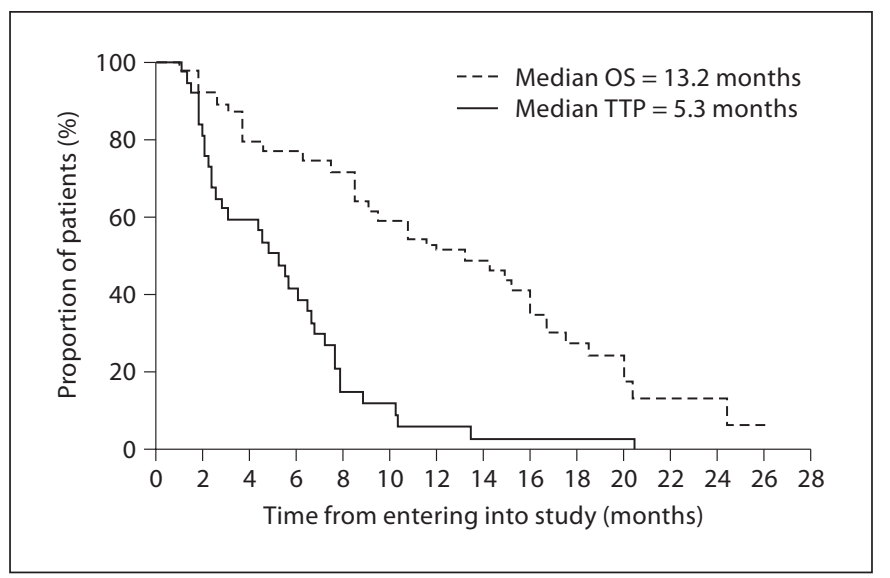

Fig. 1. Time to progression (TTP, _- ) and overall survival (OS, $---)$.

Table 4. Time-to-event parameters

\begin{tabular}{lll}
\hline Parameter & $\begin{array}{l}\text { Median } \\
\text { months }\end{array}$ & $\begin{array}{l}95 \% \text { CI } \\
\text { months }\end{array}$ \\
\hline $\begin{array}{l}\text { Remission and progression } \\
\quad \text { Time to remission }\end{array}$ & 2.6 & $1.3-5.1$ \\
$\quad$ Duration of remission & 3.3 & $3.0-5.8$ \\
$\quad \begin{array}{l}\text { Duration of stable disease } \\
\quad \text { Time to progression }\end{array}$ & 6.8 & $5.7-7.9$ \\
$\quad 5.3$ & $2.6-6.7$ \\
$\quad \begin{array}{l}\text { Survival } \\
\text { Overall survival }\end{array}$ & 13.2 & $8.7-16.7$ \\
\hline
\end{tabular}

and without prior treatment containing an anthracycline and/or a taxane.

The median time to first observation of an objective response was 2.6 months (95\% CI: 1.3-5.1 months). Median duration of response was 3.3 months (95\% CI: 3.05.8 months), and median time to progression was 5.3 months (95\% CI: 2.6-6.7 months). The median overall survival was 13.2 months (95\% CI: 8.7-16.7 months). Time to progression and overall survival are shown in figure 1. The time-to-event parameters are listed in table 4.

\section{Toxicity}

The predominant hematological toxicity was leukopenia grade $3 / 4$ which occurred in 25 (64\%) of the patients and $26 \%$ of the applied cycles. Four patients (10\%) experienced febrile neutropenia. Growth factor support was applied in 15 patients (38\%). Grade 3/4 thrombocytopenia occurred in 19 patients (49\%) and $23 \%$ of cycles, respectively. Anemia grade $3 / 4$ was less frequent (10\% of patients, $3 \%$ of cycles).

Nonhematological toxicity was considered mild to moderate. Grade 4 nonhematological toxicity was observed in 8 patients (21\%) including elevation of serum transaminases ( $3 \%$ of patients, $0.5 \%$ of cycles), elevation of $\gamma$-glutamyltransferase ( $8 \%$ of patients, $1.5 \%$ of cycles) and dyspnea ( $8 \%$ of patients, $0.5 \%$ of cycles). No grade 4 neurotoxicity and nephrotoxicity were observed. Neurotoxicity grade 1 or 2 was observed in 12 patients (31\%),

Table 5. Toxicities (number and $\%$ of patients)

\begin{tabular}{|c|c|c|c|c|c|c|c|c|c|}
\hline & \multirow{3}{*}{$\begin{array}{l}\text { Evaluable } \\
\text { patients }\end{array}$} & \multicolumn{8}{|c|}{ WHO grade } \\
\hline & & \multicolumn{2}{|l|}{1} & \multicolumn{2}{|l|}{2} & \multicolumn{2}{|l|}{3} & \multicolumn{2}{|l|}{4} \\
\hline & & $\mathrm{n}$ & $\%$ & $\mathrm{n}$ & $\%$ & $\mathrm{n}$ & $\%$ & $\mathrm{n}$ & $\%$ \\
\hline \multicolumn{10}{|l|}{ Hematological toxicity } \\
\hline Leukopenia & 39 & 1 & 3 & 12 & 31 & 23 & 59 & 2 & 5 \\
\hline Febrile neutropenia & 39 & 0 & 0 & 2 & 5 & 1 & 3 & 1 & 3 \\
\hline Thrombocytopenia & 39 & 9 & 23 & 8 & 21 & 10 & 26 & 9 & 23 \\
\hline Anemia & 39 & 10 & 26 & 25 & 64 & 4 & 10 & 0 & 0 \\
\hline \multicolumn{10}{|l|}{ Nonhematological toxicity } \\
\hline Alopecia & 39 & 6 & 15 & 16 & 41 & 3 & 8 & 0 & 0 \\
\hline Nausea/vomiting & 39 & 19 & 49 & 16 & 41 & 0 & 0 & 0 & 0 \\
\hline Asthenia & 39 & 15 & 38 & 6 & 15 & 0 & 0 & 0 & 0 \\
\hline Neurotoxicity & 39 & 8 & 21 & 4 & 10 & 0 & 0 & 0 & 0 \\
\hline Nephrotoxicity & 39 & 7 & 18 & 1 & 3 & 1 & 3 & 0 & 0 \\
\hline Alkaline phosphatase & 39 & 16 & 41 & 4 & 10 & 4 & 10 & 0 & 0 \\
\hline AST & 39 & 21 & 54 & 12 & 31 & 2 & 5 & 1 & 3 \\
\hline ALT & 39 & 16 & 41 & 11 & 28 & 5 & 13 & 0 & 0 \\
\hline Bilirubin & 39 & 2 & 5 & 2 & 5 & 4 & 10 & 0 & 0 \\
\hline
\end{tabular}


Table 6. Overview of clinical trials regarding treatment of $\mathrm{MBC}$ patients with gemcitabine and platinum salts either as single agents or in combination

\begin{tabular}{|c|c|c|c|c|c|}
\hline Reference & $\mathrm{n}$ & Regimen & OR, \% & TTP, months & OS, months \\
\hline \multicolumn{6}{|l|}{ 1st-line gemcitabine (GEM) } \\
\hline Blackstein et al. [2] & 39 & GEM & 73.1 & 5.1 & 21.1 \\
\hline \multicolumn{6}{|l|}{ 2nd-line gemcitabine (GEM) } \\
\hline \multirow[t]{2}{*}{ Brodowicz et al. [3] } & \multirow[t]{2}{*}{25} & GEM 2nd-line $(\mathrm{n}=9)$; & 22 & 5.1 & 12.6 \\
\hline & & 3rd-line $(\mathrm{n}=16)$ & 12 & 3.5 & 7.5 \\
\hline Spielmann et al. [5] & 47 & GEM & 29 & 8.1 & n.a. \\
\hline Carmichael et al. [34] & 40 & GEM 1st-/2nd-line & 25 & 1.9 & 11 \\
\hline Smorenburg et al. [35] & 23 & GEM & 0 & 1.9 & 7.8 \\
\hline \multicolumn{6}{|l|}{ 1st-line carboplatin (CBDA) } \\
\hline Kolaric and Vukas [11] & 20 & carboplatin & 20 & n.a. & n.a. \\
\hline \multicolumn{6}{|l|}{ 2nd-line carboplatin (CBDA) } \\
\hline Martin et al. $[12,13]$ & 34 & carboplatin & 35 & 8 & n.a. \\
\hline \multirow[t]{3}{*}{ O’Brien et al. [14] } & \multirow[t]{3}{*}{40} & carboplatin & 8 & \multirow[t]{3}{*}{4.5} & \multirow[t]{3}{*}{ n.a. } \\
\hline & & 1st-line $(\mathrm{n}=13)$ & 33 & & \\
\hline & & 2nd-line $(\mathrm{n}=27)$ & & & \\
\hline \multicolumn{6}{|l|}{ 1st-line GEM/cisplatin } \\
\hline Mohran [9] & 25 & GEM/cisplatin & 54.5 & n.a. & 14.8 \\
\hline Fuentes et al. [10] & 46 & GEM/cisplatin & 81 & 14.9 & 27.9 \\
\hline Alauddin and Shaharyar [36] & 30 & GEM/cisplatin & 76.7 & n.a. & n.a. \\
\hline \multicolumn{6}{|c|}{ 2nd-line GEM/cisplatin or carboplatin } \\
\hline \multirow[t]{2}{*}{ Burch et al. [37] } & \multirow[t]{2}{*}{58} & GEM/cisplatin & 29 (high dose) & 7.7 & 16.9 \\
\hline & & (2 dose levels) & 32 (low dose) & 6.5 & 13.5 \\
\hline Seo et al. [6] & 30 & GEM/cisplatin & 30 & 7 & 15 \\
\hline Heinemann et al. [7] & 38 & GEM/cisplatin & 40 & 6 & 13.5 \\
\hline Chitapanarux et al. [8] & 30 & GEM/cisplatin & 52 & n.a. & n.a. \\
\hline Moura et al. [38] & 74 & GEM/cisplatin & 30 & 7.7 & 18.3 \\
\hline Nasr et al. [21] & 30 & CEM/carboplatin & 30 & 5.1 & n.a. \\
\hline Nagourney et al. [20] & 12 & GEM/carboplatin & 50 & 5 & n.a. \\
\hline Latini et al. [19] & 13 & GEM/carboplatin & 69.2 & n.a. & n.a. \\
\hline Silva et al. [33] & 19 & GEM/carboplatin & 21.5 & n.a. & 7.5 \\
\hline
\end{tabular}

TTP = Time to progression; OS = overall survival; GEM = gemcitabine; .. . $=$ not available.

and nephrotoxicity grade $1-2$ was documented in 8 patients (21\%). Hematological and nonhematological toxicities are shown in table 5.

\section{Discussion}

With the increasing use of anthracycline- and taxanebased regimens in the adjuvant and neoadjuvant setting and their established application in the treatment of the advanced and metastatic stages of breast cancer, there is a clear need for non-cross-resistant further-line regimens. While there is no established standard of chemotherapy for anthracycline- and taxane-pretreated patients, capecitabine has become a widely accepted agent in this treatment setting. In phase II and III trials re- sponse rates in the range of $26-52 \%$ and time to progression of 3.6-8.9 months were reported [26-30].

The preclinical rationale for a combination of gemcitabine with a platinum analog is supported by the synergistic interaction of both agents [17, 18,31]. Several clinical studies performed with various schedules have demonstrated that the combination of gemcitabine and cisplatin is highly active not only in first-line treatment, but also in patients previously exposed to anthracyclines and/or taxanes (table 6). While a formal comparison of carboplatin and cisplatin has never been performed in $\mathrm{MBC}$, the available evidence suggests a better tolerability of carboplatin [32]. Due to its lower emetogenic and nephrotoxic potential carboplatin may be specifically preferred in intensively pretreated patients. Moreover, time-consuming hydration regimens can be avoided with carboplatin. 
The present study evaluated a 3-week regimen, where gemcitabine was applied on days 1 and 8 , while carboplatin was given on day 1 . Most patients had undergone previous treatment with anthracyclines (67\%) and/or taxanes (64\%). The efficacy of gemcitabine plus carboplatin (overall response rate 31\%, 95\% CI: $17-48 \%$ ) reached the predefined endpoint of a clinically relevant activity. The median duration of most responses and disease stabilizations was 3.3 and 6.8 months, respectively. The median time to progression was 5.3 months resulting in a median overall survival of 13.2 months.

Comparable results have also been reported by Nasr et al. [21] who investigated a schedule where gemcitabine $\left(1,000 \mathrm{mg} / \mathrm{m}^{2}\right.$, days $\left.1+8\right)$ and a greater dose of carboplatin (AUC 5 on day 1) were applied in a 3-week regimen. The combination was given to $30 \mathrm{MBC}$ patients as a second-line treatment. The overall response rate was $30 \%$ and median time to progression was 4.8 months. Main grade $3 / 4$ hematological toxicities were neutropenia in $50 \%$ of patients ( $20 \%$ of whom had febrile neutropenia), anemia in $26.6 \%$ and thrombocytopenia in $30 \%$ of patients.

The same schedule was evaluated by Silva et al. [33] in 19 comparably pretreated $\mathrm{MBC}$ patients yielding an overall response rate of $21.5 \%$ and a median overall survival of 7.5 months. Main hematological toxicities included anemia ( $21 \%$ of patients), neutropenia (21\%), and thrombocytopenia in $5 \%$ of patients.

Nagourney et al. [20] reported a 'repeating doublet' regimen, where gemcitabine $\left(800 \mathrm{mg} / \mathrm{m}^{2}\right)$ and carboplatin (AUC 2) were both applied on days 1 and 8 of a 3-week regimen. Ten evaluable patients with first or second recurrence of $\mathrm{MBC}$ had received the schedule with an overall response rate of $50 \%$ (including 1 complete response) and a median time to progression of 5 months (range 220 months). Most commonly reported grade 3 and 4 side effects were neutropenia (60\% of patients) and thrombocytopenia ( $40 \%$ of patients).

The treatment-associated toxicity profile in our study was generally acceptable. Hematological toxicity (grade 3 and 4), mainly leukopenia and thrombocytopenia, occurred in 26 and $23 \%$ of the applied cycles, respectively. The rate of febrile neutropenia was low ( $6 \%$ of patients) as compared to an incidence of $20 \%$ in the study by Nasr et al. [21]. As a consequence, a median of five cycles could be administered without significant delays or dose reductions. Nevertheless, $38 \%$ of the patients required hematopoietic growth factor support. This is in part explained by the intensive pretreatment observed in most of the patients. Thus, for the considerable incidence of severe thrombocytopenia it would be reasonable to consider starting gemcitabine at the lower dose level of 800 $\mathrm{mg} / \mathrm{m}^{2}$. Symptomatic adverse events such as nausea/ vomiting or asthenia were generally mild to moderate. There was no patient who developed renal dysfunction ( $\geq$ grade 2 ).

Certainly, an optimal regimen of gemcitabine/carboplatin for intensively pretreated MBC patients has not been determined in a comparative fashion. It appears, however, that the application of carboplatin on day 1 may be preferred to the repeating doublet regimen since the latter was associated with a higher incidence of hematological toxicity (neutropenia 26 vs. $60 \%$, thrombocytopenia 23 vs. $40 \%$ ).

In conclusion, the combination of gemcitabine plus carboplatin is a generally well-tolerated and effective regimen that provided sustained disease control in intensively pretreated breast cancer patients. Specifically after previous exposure to anthracyclines and/or the taxanes, this regimen can be considered as an active treatment option which offers a favorable balance between efficacy and tolerability.

\section{References}

1 Heinemann V: Role of gemcitabine in the treatment of advanced and metastatic breast cancer. Oncology 2003;64:191-206.

2 Blackstein M, Vogel CL, Ambinder R, Cowan J, Iglesias J, Melemed A: Gemcitabine as first-line therapy in patients with metastatic breast cancer: a phase II trial. Oncology 2002;62:2-8

3 Brodowicz T, Kostler WJ, Moslinger R, et al: Single-agent gemcitabine as second- and third-line treatment in metastatic breast cancer. Breast 2000;9:338-342.
4 Modi S, Currie VE, Seidman AD, et al: A phase II trial of gemcitabine in patients with metastatic breast cancer previously treated with an anthracycline and taxane. Clin Breast Cancer 2005;6:55-60.

5 Spielmann M, Llombart-Cussac A, Kalla S, et al: Single-agent gemcitabine is active in previously treated metastatic breast cancer. Oncology 2001;60:303-307.

6 Seo JH, Oh SC, Choi CW, et al: Phase II study of a gemcitabine and cisplatin combination regimen in taxane resistant metastatic breast cancer. Cancer Chemother Pharmacol 2007; 59:269-274
7 Heinemann V, Stemmler HJ, Wohlrab A, et al: High efficacy of gemcitabine and cisplatin in patients with predominantly anthracycline- and taxane-pretreated metastatic breast cancer. Cancer Chemother Pharmacol 2006;57:640-646.

8 Chitapanarux I, Lorvidhaya V, Kamnerdsupaphon P, et al: Gemcitabine plus cisplatin (GC): a salvage regimen for advanced breast cancer patients who have failed anthracycline and/or taxane therapy. Gan To Kagaku Ryoho 2006;33:761-766. 
9 Mohran TZ: Gemcitabine and cisplatin combination chemotherapy as a first-line treatment in patients with metastatic breast cancer. J Egypt Natl Cancer Inst 2004;16:8-14.

10 Fuentes H, Calderillo G, Alexander F, et al: Phase II study of gemcitabine plus cisplatin in metastatic breast cancer. Anticancer Drugs 2006;17:565-570.

11 Kolaric K, Vukas D: Carboplatin activity in untreated metastatic breast cancer patients - results of a phase II study. Cancer Chemother Pharmacol 1991;27:409-412.

12 Martin M, Diaz-Rubio E, Casado A, Lopez Vega JM: Phase II study of carboplatin in advanced breast cancer: preliminary results. Semin Oncol 1991;18(1 suppl 2):23-27.

13 Martin M, Diaz-Rubio E, Casado A, et al: Carboplatin: an active drug in metastatic breast cancer. J Clin Oncol 1992;10:433437.

14 O’Brien ME, Talbot DC, Smith IE: Carboplatin in the treatment of advanced breast cancer: a phase II study using a pharmacokinetically guided dose schedule. J Clin Oncol 1993;11:2112-2117.

15 Go RS, Adjei AA: Review of the comparative pharmacology and clinical activity of cisplatin and carboplatin. J Clin Oncol 1999;17: 409-422.

16 Iaffaioli RV, Tortoriello A, Facchini G, et al: Phase I-II study of gemcitabine and carboplatin in stage IIIB-IV non-small-cell lung cancer. J Clin Oncol 1999;17:921-926.

17 Peters GJ, Bergman AM, Ruiz van Haperen VW, Veerman G, Kuiper CM, Braakhuis BJ: Interaction between cisplatin and gemcitabine in vitro and in vivo. Semin Oncol 1995; 22(4 suppl 11):72-79.

18 van Moorsel CJ, Veerman G, Bergman AM, et al: Combination chemotherapy studies with gemcitabine. Semin Oncol 1997;24(2 suppl 7):S7-17-S7-23.

19 Latini L, Torresi U, Valeri M, Pistilli B: Carboplatin-gemcitabine combination in anthracyclines- and/or taxanes-resistant metastatic breast cancer (abstract). J Clin Oncol ASCO Annual Meeting Proceedings 2003; 22:318.
20 Nagourney RA, Link J, Sommers B, et al: Carboplatin and gemcitabine repeating doublet in recurrent breast cancer. J Clin Oncol ASCO Annual Meeting Proceedings 2004; 22(14S):851

21 Nasr FL, Chahine GY, Kattan JG, et al: Gemcitabine plus carboplatin combination therapy as second-line treatment in patients with relapsed breast cancer. Clin Breast Cancer 2004;5:117-122, 123-124.

22 Stemmler HJ, Kahlert S, Brudler O, et al: High efficacy of gemcitabine and cisplatin plus trastuzumab in patients with HER2overexpressing metastatic breast cancer: a phase II study. Clin Oncol (R Coll Radiol) 2005;17:630-635.

23 Ajani JA, Welch SR, Raber MN, Fields WS Krakoff IH: Comprehensive criteria for assessing therapy-induced toxicity. Cancer Invest 1990;8:147-159.

24 Kaplan EL, Meier P: Nonparametric estimation from incomplete observations. J Am Stat Assoc 1959;53:457-481.

25 Simon R: Optimal two-stage designs for phase II clinical trials. Control Clin Trials 1989; 10:1-10.

26 Lee SH, Lee J, Park J, et al: Capecitabine monotherapy in patients with anthracycline- and taxane-pretreated metastatic breast cancer. Med Oncol 2004;21:223-231.

27 Ahn JH, Kim SB, Kim TW, et al: Capecitabine and vinorelbine in patients with metastatic breast cancer previously treated with anthracycline and taxane. J Korean Med Sci 2004; 19:547-553.

28 Wist EA, Sommer HH, Ostenstad B, Risberg T, Bremnes Y, Mjaaland I: Oral capecitabine in anthracycline- and taxane-pretreated advanced/metastatic breast cancer. Acta Oncol 2004;43:186-189.

29 Batista N, Perez-Manga G, Constenla M, et al: Phase II study of capecitabine in combination with paclitaxel in patients with anthracycline-pretreated advanced/metastatic breast cancer. Br J Cancer 2004;90:17401746.
30 Oshaughnessy JA, Blum J, Moiseyenko V, et al: Randomized, open-label, phase II trial of oral capecitabine (Xeloda) vs. a reference arm of intravenous CMF (cyclophosphamide, methotrexate and 5-fluorouracil) as first-line therapy for advanced/metastatic breast cancer. Ann Oncol 2001;12:12471254.

31 Achanta G, Pelicano H, Feng L, Plunkett W, Huang P: Interaction of p53 and DNA-PK in response to nucleoside analogues: potential role as a sensor complex for DNA damage. Cancer Res 2001;61:8723-8729.

32 Lokich J, Anderson N: Carboplatin versus cisplatin in solid tumors: an analysis of the literature. Ann Oncol 1998;9:13-21.

33 Silva JA, Perez Michel LM, Gallardo Rincon D: Gemcitabine plus carboplatin in recurrent and advanced breast cancer: a phase II trial. J Clin Oncol ASCO Annual Meeting Proceedings 2004;22(14S):877.

34 Carmichael J, Possinger K, Phillip P, et al: Advanced breast cancer: a phase II trial with gemcitabine. J Clin Oncol 1995;13:27312736

35 Smorenburg CH, Bontenbal M, Seynaeve C, et al: Phase II study of weekly gemcitabine in patients with metastatic breast cancer relapsing or failing both an anthracycline and a taxane. Breast Cancer Res Treat 2001;66: 83-87.

36 Alauddin A, Shaharyar A: Gemcitabine and cisplatin combination chemotherapy as first-line treatment in patients with metastatic breast cancer (abstract). J Clin Oncol ASCO Annual Meeting Proceedings 2005; 23(16S):713

37 Burch PA, Mailliard JA, Hillman DW, et al: Phase II study of gemcitabine plus cisplatin in patients with metastatic breast cancer: a North Central Cancer Treatment Group Trial. Am J Clin Oncol 2005;28:195-200.

38 Moura GL, Pasquini R, Frare A, Vianna K, Albini L, Padilha S: Gemcitabine and cisplatin in metastatic breast cancer (abstract). J Clin Oncol ASCO Annual Meeting Proceedings 2007;25(18S):1084. 